the requirements of journals. The first would obviously be "adverse drug reaction," followed by the nature of the reaction (and if necessary the organ affected when this is not obvious from the wording of the nature of the reaction) and by the generic name of the suspected drug. Optional key words could be the chemical or therapeutic class and the mechanism. An example is "adverse drug reaction, skin, urticaria, ampicillin, $\beta$-lactamines, hypersensitivity." Standardised coding would greatly facilitate the retrieval of information on drug reactions by prescribers, pharmaceutical companies, and anyone else with an interest in the subject.

J M BONNETBLANC

Department of Dermatology,
University Hospital Dupuytren,
87042 Limoges cedex,
France

J C ROUJEAU Professor

Department of Dermatology,

University Hospital Henri Mondor,

994010 Créteil cedex

BENICHOU

Director

nternational Drug Monitoring Department,

Synthelabo,

BP 110 ,

92225 Bagneux cedex

\section{Endogenous sex hormones and cardiovascular disease in postmenopausal women}

\section{Other sources of variability should have been taken into account}

EdroR,-Elizabeth Barret-Connor and Deborah Goodman-Gruen did not find any association between endogenous sex hormones and the risk of death from cardiovascular and ischaemic heart disease in a cohort study of 651 postmenopausal women living in Rancho Bernardo, California.' To study this association the authors measured serum concentrations of androstenedione, total and bioavailable testosterone, oestrone, and total and bioavailable oestradiol in specimens collected at the baseline and stored at $-70^{\circ} \mathrm{C}$ for 10 years. They took into consideration two methodological issues (long term stability of hormones in stored serum at very low temperatures and hormone variability within and among subjects). They did not, however, consider two other important methodological issues.

The first issue relates to the effect of long term storage on the bioavailable fraction of oestradiol. While there is a general consensus on the long term stability of sex hormones stored at very low temperatures, evidence suggests that the bioavailable fraction of hormones in stored specimens increases with time. For example, we have shown that bioavailable testosterone increased up to $30 \%$ of the initial concentration over three years' storage at $-70^{\circ} \mathrm{C}$; this increase was interpreted as being due to progressive dissociation of the steroid-protein complex in frozen serum. ${ }^{2}$ Other evidence for such dissociation is provided by Langley et al, who reported that the cleavage of oestradiol from sex hormone binding globulin increases with time in frozen serum samples. ${ }^{3}$

The second issue concerns controlling for another form of hormone variability: the circadian rhythm. In the authors' study blood samples were collected between 730 and $11 \mathrm{am}$. Production of hormones is characterised by strong circadian fluctuation, and important differences have been detected between early and late morning. ${ }^{4}$ Adjustment for the exact time at which blood was drawn (not mentioned in the authors' paper) could help in controlling for this possible source of error.

In conclusion, study of the relation between hormones and chronic disease is made particularly difficult by numerous sources of variability Careful attention should be paid to these before conclusive statements can be made regarding the possible lack of an aetiological role for hormones in chronic disease.

PAOLA MUT Assistant professo MAURIZIO TREVISAN

Department of Social and Preventive Medicine Professor State University of New York at Buffalo, Buffalo, NY, USA

1 Barrett-Connor E, Goodman-Gruen D. Prospective study of endogenous sex hormones and fatal cardiovascular disease in postmenopausal women. $B M 7$ 1995;311:1193-6. (4 November.)

2 Bolelli GF, Muti P, Micheli A, Sciajno R, Franceschetti F, Krogh $V$, et al Validity for epidemiological studies of longP. serum and in plasma. Cancer Epidemiol Biomarkers Prev 1995;4:509-13.

3 Langley MS, Hammond GL, Bardsley A, Seliwood RA, Anderso DC. Serum steroid binding proteins and the bioavailability of estradiol in relation to breast diseases. $f$ Natl Cancer Inst 1985;75:823-9.

4 Panico S, Pisani P, Muti P, Recchione C, Cavalleri A, Totis A, et al. Diurnal variation of testosterone and estradiol: a source of bias in comparative studies on breast cancer. 7 Endocrinol Invest 1990;13:423-6.

\section{Authors' reply}

EdToR,-Paola Muti and Maurizio Trevisan are concerned that the absence of any association between oestrogen concentration and the risk of fatal cardiovascular disease in our study may have been due to dissociation of bioavailable oestrogen in the frozen samples over time. The papers they cite raise the possibility of dissociation but do not prove it.

Bolelli $e t$ al studied frozen plasma $\left(-80^{\circ} \mathrm{C}\right)$ from eight postmenopausal women. ${ }^{1}$ Over three year the women maintained the same rank for all hormone concentrations: this rather than the absolute value would be all that is necessary for showing an association in epidemiological studies. Although free testosterone (non-sex hormone binding globulin or albumin bound measured with a commercial coated tube radioimmunoassay kit) showed a $30 \%$ increase between the baseline and one year, this increase (within the coefficient of variation) did not change thereafter, suggesting that longer freezing would not have changed the results of the assay further.

Langley et al indirectly measured the rate of dissociation of dihydrotestosterone from sex hormone binding globulin in 15 women, whose menopausal status was not given. ${ }^{2}$ In these serum samples, stored at $-20^{\circ} \mathrm{C}$, the dissociation rate seemed to increase over 180 days, which is compatible with the early change reported by Bolell et al.

Even if concentrations of bioavailable oestradiol do change over time in frozen samples, in our study, with plasma frozen at $-80^{\circ} \mathrm{C}$, the correlation of total oestradiol with bioavailable oestradiol was $0.97(P=0.001)$. We still think that our study makes an association between endogenous oestrogen and coronary heart disease most unlikely in postmenopausal women.

ELIZABETH BARRETT-CONNOR Professor

DEBORAH GOODMAN-GRUEN Medical fellow

Department of Family and Preventive Medicine,

University of California,

San Diego,

L Jolla, CA 92093-0607,

USA

1 Bolelli GF, Muti P, Micheli A, Sciajno R, Franceschetti F, Krogh V, et al. Validity for epidemiological studies of long term cryoconservation of steroid and protein hormones in serum and in plasma. Cancer Epidemiol Biomarkers Prev 1995;4:509-13.

2 Langley MS, Hammond GL, Bardsley A, Seliwood RA, Anderson DC. Serum steroid binding proteins and the bioavailability of estradiol in relation to breast diseases $f$ Natl Cancer Inst 1985;75:823-9.

\section{Hepatitis B vaccination}

\section{Information for patients is vital}

EDrTOR,-P Mantagni and colleagues highlight the need to improve access to hepatitis $B$ vaccination within services for intravenous drug users. ${ }^{1}$ Experience of vaccination in genitourinary medicine clinics, which offer an established access point for target groups, has shown that access is only one part of the process of effective vaccination. ${ }^{2}$ It is vital that services offering the vaccine provide effective information for patients and monitor participants from initial to final vaccination. We present audit data showing the importance of identifying drop out rates, gaps in the delivery of information, and patients' knowledge of the vaccine schedule.

A preliminary audit at the genitourinary medicine clinics of University College and the Middlesex Hospitals showed that, despite good access, two thirds of patients who started the six month vaccine course did not complete it. This means that, at a cost of $£ 11.93$ per dose, over $£ 600$ worth of vaccine may be ineffectively used for every 100 clients starting the course.

A second audit of patients attending University College Hospital's clinic for vaccination explored patients' knowledge of the vaccine schedule and the delivery of information. A questionnaire completed by 66 consecutive patients showed that 49 did not know when their second and third doses were due, 40 did not know that a blood test was needed after vaccination, and 32 did not know that a booster was needed at a later date. Only six knew all of these facts, and $18 \mathrm{knew}$ none of them.

Most patients reported that the vaccine schedule had been discussed in the clinic, but many different staff groups were involved (doctor, 26; doctor and nurse, 13; nurse, 11; doctor, nurse, and health adviser, 7; health adviser, 5; doctor and health adviser, 2; nurse and health adviser, 2). Most patients (40) had received an information leaflet about hepatitis B. This, however, had come from a variety of sources: doctors, nurses, health advisers, and the waiting room. None of the three leaflets available detailed the vaccination schedule. A complementary leaflet was developed during the audit and is available on request.

High drop out rates for the hepatitis $B$ vaccination schedule are expensive, not only financially but also for individual and public health Educating patients effectively is one factor that can and should be optimised; staff need the time and skills to do this. This requires training and resources.

Department of Genitourinary Medicine,
St Mary's Hospital,

ANNA PALIECAROS

London W/2 1NY Clinical research fellow

Department of Genitourinary Medicine,

ANGELA ROBINSON Consultant physician

University College Hospital

London WC1E 6AU

1 Mangtani P, Kovats S, Hall A. Hepatitis B vaccination policy in drug treatment services. $B M M^{\prime}$ 1995;311:1500. (2 December.)

2 Bhatti N, Gilson UC, Beecham M, Williams P, Matthews MP, Tedder RS, et al. Failure to deliver hepatitis $B$ vaccination confessions of a Genitourinary Medicine clinic. BMf 1991 303:97-100.

\section{All GPs in Brent and Harrow offer hepatitis $B$ vaccination to drug users}

EDrToR,-In their survey of the hepatitis B vaccination policies of treatment services for injecting drug users $\mathbf{P}$ Mangtani and colleagues do not mention general practice. ${ }^{1}$ Colleagues and I have just audited the treatment of drug users in general practice in Brent and Harrow before starting a training programme and an incentive scheme for general practitioners willing to prescribe substi- 